В Е С Т НИК ПНИП У

DOI: $10.15593 / 2224-9877 / 2016.1 .05$

УДК 621.763

\author{
Ж.Г. Ковалевская ${ }^{1,2}$, М.А. Химич ${ }^{1,3}$, \\ Ю.П. Шаркеев ${ }^{1,2}$, Е.В. Бабакова ${ }^{4}$ \\ ${ }^{1}$ Институт физики прочности и материаловедения СО РАН, Томск, Россия \\ ${ }^{2}$ Национальный исследовательский Томский политехнический \\ университет, Томск, Россия \\ ${ }^{3}$ Национальный исследовательский Томский государственный \\ университет, Томск, Россия \\ ${ }^{4}$ Юргинский технологический институт Национального исследовательского \\ Томского политехнического университета, Юрга, Россия
}

\author{
СТРУКТУРА И ФАЗОВЫЙ СОСТАВ \\ СПЛАВА Ti-Nb, ПОЛУЧЕННОГО СЕЛЕКТИВНЫМ \\ ЛАЗЕРНЫМ СПЛАВЛЕНИЕМ
}

\begin{abstract}
Рассмотрены особенности структуры и фазового состава сплава $\mathrm{Ti}-40$ мас. \% Nb, полученного в процессе селективного лазерного сплавления. Сплав такого состава имеет наименьший модуль упругости среди сплавов системы Ti-Nb и применяется в качестве материала для медицинских имплантатов.

Методами рентгеноструктурного анализа, растровой электронной микроскопии и энергодисперсионного микроанализа изучено строение образцов, состоящих из одного и восьми слоев, полученных при одинаковых режимах селективного лазерного сплавления. Показано, что сплав состоит из двух фраз: равновесной $\beta-\mathrm{Ti}-\mathrm{Nb}$ и неравновесной $\alpha^{\prime \prime}-$ фазы. Наличие a"-фразы обусловлено неравновесными условиями охлаждения и кристаллизации материала. Строение многослойного образца повторяет строение монослоя. Монослой, в свою очередь, имеет градиентное строение. По высоте монослоя меняется размер зерна и пористость. Изменение размера зерна в монослое составляет 1-35 мкм. Размер зерна плавно возрастает от нижней границы зоны сплавления к верхней. В нижней зоне сплавления образуются газовые поры округлой формы с размерами 1-10 мкм. Поры располагаются на границах зерен. В верхней зоне сплавления пор наблюдается меньше. Градиентное строение монослоя определяется условиями теплоотвода. Чем дальше от поверхности контакта луча с порошком, тем крупнее зерно и меньше пористость. В многослойном образце транслируется структура монослоя.

При проведении процесса селективного лазерного сплавления рекомендуется создавать такие условия охлаждения и кристаллизации расплавившегося материала, при которых весь объем слоя, а значит, и всего изделия, будет иметь структуру, подобную верхней зоне монослоя с достаточно мелким зерном и незначительной пористостью.
\end{abstract}

Ключевые слова: аддитивные технологии, селективное лазерное сплавление, медицинские имплантаты, сплав Ti-Nb, $\beta-\mathrm{Ti}-\mathrm{Nb}, \alpha^{\prime \prime}-$ фраза, монослой, градиентное строение, зерно, пористость, теплоотвод. 


\author{
Zh.G. Kovalevskaia ${ }^{1,2}$, M.A. Khimich ${ }^{1,3}$, \\ lu.P. Sharkeev ${ }^{1,2}$, E.V. Babakova ${ }^{4}$ \\ ${ }^{1}$ Institute of Strength Physics and Materials Science of the Siberian Branch \\ of the Russian Academy of Sciences, Tomsk, Russian Federation \\ ${ }^{2}$ National Research Tomsk Polytechnic University, Tomsk, Russian Federation \\ ${ }^{3}$ National Research Tomsk State University, Tomsk, Russian Federation \\ ${ }^{4}$ Yurga Institute of Technology of National Research Tomsk \\ Polytechnic University Affiliate, Yurga, Russian Federation

\section{STRUCTURE AND PHASE COMPOSITION OF Ti-Nb ALLOY PRODUCED BY THE METHOD OF SELECTIVE LASER MELTING}

\begin{abstract}
Features of the structure and phase composition of Ti- 40 mas \% Nb obtained in the process of selective laser melting were investigated in this paper. The alloy of such a composition has the lowest Young's modulus among Ti-Nb alloys system and is applied as a material for medical implants.

The structure of the specimens consisting of one and eight layers obtained at the same conditions of selective laser melting are studied by the methods of X-ray diffraction, scanning electron microscopy and energy-dispersive microanalysis. It is shown that the alloy consists of two phases. They are equilibrium $\beta-\mathrm{Ti}-\mathrm{Nb}$ and non-equilibrium $\alpha^{\prime \prime}$-phase. Presence of $\alpha^{\prime \prime}$-phase is caused by nonequilibrium conditions of cooling and crystallization of material. The structure of multi-layered specimen repeats structure of monolayer. Monolayer in turn has gradient structure. Throughout the height of the monolayer the grain size and porosity change. Grain size of monolayer is in the range of 1-35 $\mu \mathrm{m}$. Grain size slightly increases from low to up boundary of alloying zone. Circular form pinholes with the size 1-10 $\mu \mathrm{m}$ are formed in the low alloying zone. Pores are situated on the grains boundaries. There is less number of pores in the up alloying zone. The gradient structure of monolayer is defined by conditions of heatsink. With the growth of the distance from the surface of the contact with the powder the grain size becomes larger and the porosity becomes smaller. The multilayer structure is translated monolayer structure.

It is recommended in the process of selective laser melting to create such conditions of cooling and crystallization of melted material when the bulk of the layer has the structure similar to the up zone of monolayer with sufficiently fine grain and low porosity.
\end{abstract}

Keywords: additive technologies, selective laser melting, medical implants, Ti-Nb alloy, $\beta-\mathrm{Ti}-\mathrm{Nb}$, $\alpha^{\prime \prime}$-phase, monolayer, gradient structure, grain, porosity, heatsink.

\title{
Введение
}

Сплавы на основе титана получили широкое распространение в области медицины. Среди прочих особое место занимают биоинертные сплавы системы Ti-Nb. Их физико-механические характеристики, прежде всего низкий модуль упругости и биоинертные свойства, определили их применение в производстве медицинских имплантатов [1-4]. Однако указанные сплавы имеют и свои недостатки. Стоимость титана 
и ниобия достаточно высока, что увеличивает и стоимость готовых изделий. Использование аддитивных технологий, например селективного лазерного сплавления (СЛС), значительно уменьшает расход материала и, следовательно, стоимость изделий [5, 6]. Методом СЛС можно получать изделия высокой плотности, а также задавать в изделии пористость требуемого уровня [7-10]. Главным достоинством применения метода СЛС для медицинской имплантологии, наряду с другими аддитивными технологиями, является возможность создания изделий точной формы, повторяющих фрагменты человеческой кости [11].

В процессе СЛС происходит послойное сплавление исходного материала лазерным лучом. Обычно СЛС осуществляется в защитной среде; возможна подача азота или аргона, а также реализация процесса сплавления в вакууме. В качестве исходного материала используются порошки, которые могут предварительно подогреваться непосредственно перед началом процесса. Для реализации СЛС необходимы мелкодисперсные порошки, способные быстро затвердевать. Изделие формируется на платформе в замкнутой камере. Ровный слой порошкового материала подается из бункера, после чего луч лазера, проходя по заданной траектории, спекает участки порошка в виде треков с наложением друг на друга, формируя единичный слой изделия. Для формирования следующего слоя платформа опускается на расстояние, равное величине этого слоя. Затем процедура повторяется до тех пор, пока изделие необходимых размеров и формы не будет готово. Когда изделие готово, излишки порошка удаляются встряхиванием и/или зачисткой и могут впоследствии быть использованы повторно [5, 12].

Задачей данного исследования было изучение особенностей формирования в процессе СЛС фазового состава и структуры сплава состава $\mathrm{Ti}-40$ мас. \% $\mathrm{Nb}$.

\section{Материалы и методы исследования}

Из всех сплавов системы Ti-Nb наименьшим модулем упругости обладает сплав состава Ti-40 мас. \% Nb [1], поэтому данный состав был выбран для формирования сплава методом СЛС. В качестве исходного материала использовались порошки технически чистого титана марки ПТМ и ниобия марки НПБ-а.

В процессе сплавления два исходных компонента - Ti и $\mathrm{Nb}-$ должны сформировать сплав с однородным элементным и фазовым со- 
ставом, с мелкозернистой структурой и с требуемыми физико-механическими характеристиками. Эта задача требует предварительной подготовки материала, так как, во-первых, порошки $\mathrm{Ti}$ и $\mathrm{Nb}$ в процессе высокоскоростного сплавления не успевают полностью взаимодействовать друг с другом. Во-вторых, они имеют значительно различающиеся температуры плавления. С целью решения данных проблем формирования сплава при СЛС порошки Тi и $\mathrm{Nb}$ предварительно смешивались в шаровой мельнице АГО-2С в течение 15 мин. В результате получался композитный порошок требуемого состава Тi-40 мас. \% $\mathrm{Nb}$ овальной формы с размером частиц 5-60 мкм, что соответствует требованиям к порошкам для СЛС [5].

СЛС выполнялось на установке ВАРИСКАФ 100МВ [13]. Порошковый материал насыпался на подложку из титана ВТ1-0. Режим СЛС: мощность - 105 Вт, скорость сканирования лучом лазера - 2000 мм/мин, диаметр пятна - 0,7 мм, шаг сканирования - 0,1 мм, температура подложки в начале сплавления $-200{ }^{\circ} \mathrm{C}$. Для определения толщины формируемого монослоя СЛС проводили на насыпке из порошка толщиной 0,5 мм. При увеличении количества сплавляемых слоев была выбрана толщина насыпки из эксперимента, и она составила 0,2 мм. Исследовались образцы, состоящие из одного и восьми слоев. Для каждого последующего слоя направление сканирования изменялось на $90^{\circ}$.

Исследования проводились на оборудовании ЦКП «НАНОТЕХ» ИФПМ СО РАН: рентгеновский дифрактометр ДРОН-7 («Буревестник», Россия), растровый электронный микроскоп LEO EVO 50 (Zeiss, Германия); и ЦКП «Лаборатория электронной микроскопии» НГТУ (г. Новосибирск): растровый электронный микроскоп Zeiss EVO 50 XVP (Zeiss, Германия). Исследована структура полученных методом СЛС образцов сплава $\mathrm{Ti}-40$ мас. \% Nb.

\section{Результаты эксперимента и их обсуждение}

Как видно на оптическом изображении поверхности монослоя (рис. $1, a$ ), в результате движения лазерного пучка по заданной траектории материал на поверхности кристаллизуется наложенными друг на друга треками.

Присутствие пор и полостей обусловлено эффектом каплеобразования в процессе плавления и кристаллизации материала насыпки [14]. Топография поверхности многослойного образца (рис. 1 , б) частично 
повторяет топографию монослоя, поскольку каждый формирующийся слой в многослойном образце укладывается на поверхность предыдущего слоя с повторением схемы формирования монослоя.

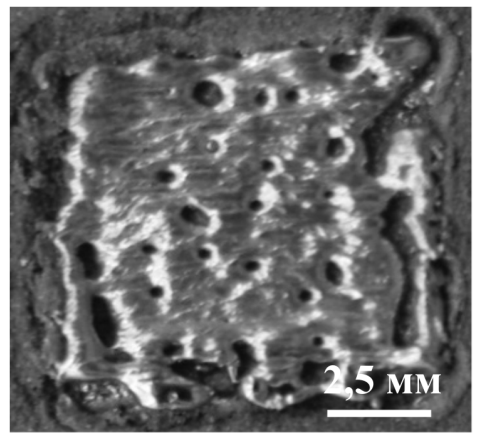

$a$

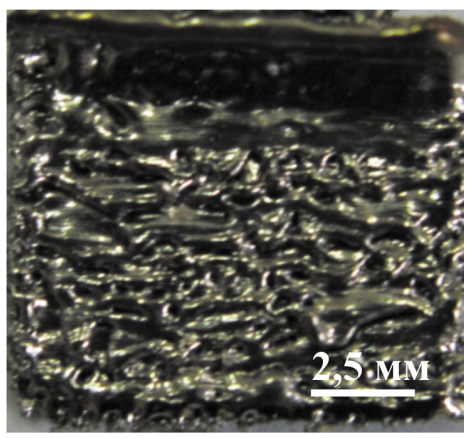

$\sigma$

Рис. 1. Оптические изображения поверхностей монослойного (a) и многослойного (б) образцов сплава $\mathrm{Ti}-\mathrm{Nb}$

Как показала РЭМ поперечного излома монослоя (рис. 2), сплавление материала происходит не на всю глубину насыпки. Нижняя часть насыпанного порошка спекается, образуя связи лишь по границе между отдельными частицами порошка (зона спеченного порошка). Выше следует полностью расплавленный и кристаллизовавшийся материал, в котором различима структурная зона с размером зерен от 2 до 8 мкм (нижняя зона сплавления) и вторая зона с размером зерна до 24 мкм (верхняя зона сплавления).

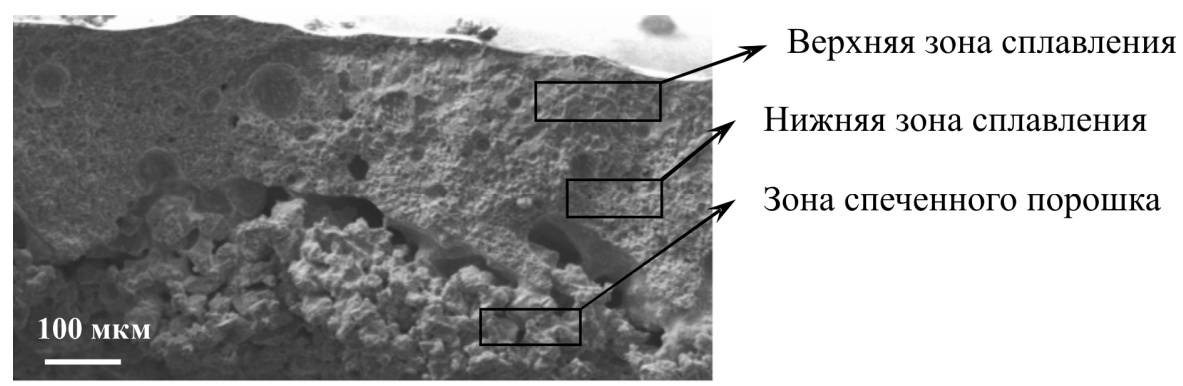

Рис. 2. РЭМ-изображение поверхности излома монослоя

Во всем монослое присутствуют поры. В зоне спеченного порошка пористость определяется насыпной плотностью материала до спекания с учетом усадки в процессе спекания. Поры формируются в про- 
странстве между спекшимися частицами и имеют неправильную разветвленную форму. На границе между спекшимся и расплавленным материалом формируются усадочные раковины размером до 30 мкм, образованные за счет усадки жидкого металла. Поры образуются и внутри закристаллизованного материала. В нижней зоне сплавления образуются газовые поры округлой формы с размером от 1 до 10 мкм. Поры располагаются на границах зерен. В верхней зоне сплавления пор меньше. Между нижней и верхней зонами сплавления располагаются крупные газовые поры размером от 20 до 60 мкм.

Несмотря на визуально наблюдаемую разнозернистость нижней и верхней зон сплавления, анализ размера зерна методом секущих показал, что общий разброс значений размера зерна в монослое составляет 1-35 мкм. Как видно на гистограмме, бимодального характера распределения зерен по размерам не наблюдается, что указывает на отсутствие в монослое разнозернистости. Размер зерна плавно возрастает от нижней зоны сплавления к верхней. При этом во всем объеме слоя присутствует часть мелких зерен размером от 2 до 10 мкм и часть зерен, размер которых возрастает в верхней зоне сплавления (рис. 3 ).

Из градиентного по глубине строения монослоя следует, что процесс нагрева, охлаждения и кристаллизации сплава проходит в температурно-временном интервале. При воздействии лазерного луча осуществляется плавление большей части порошкового материала, расположенного ближе к источнику нагрева - в верхней части насыпки. В зоне нерасплавленного материала происходят нагрев, усадка и спекание частиц порошка по границам. В результате образуется нижняя зона монослоя с губчатым строением. Охлаждение жидкого металла начинается на границе раздела «спеченный слой - жидкость». Теплоотвод идет в сторону зоны спеченного порошка и подложки. В обратном направлении, от границы со спеченным порошковым материалом, происходит кристаллизация, за счет чего образуются крупные усадочные поры. В нижней части кристаллизующейся ванны высокие скорости охлаждения обеспечивают формирование мелкозернистой структуры с включениями по границам зерен мелких газовых пор. В верхней части кристаллизующейся ванны, где теплоотвод в подложку затруднен, условия охлаждения обеспечивают более равновесные условия кристаллизации материала. В результате в верхней части монослоя образуется структура с большим размером зерна и с незначительной пористостью. 


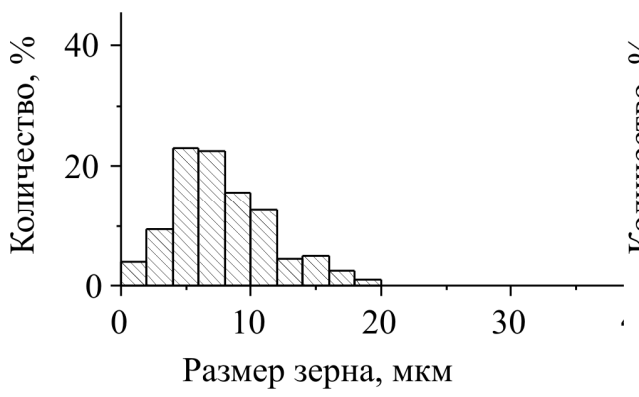

$a$

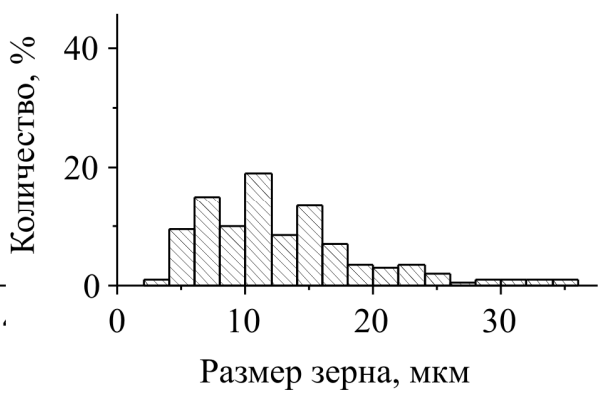

$\sigma$

Рис. 3. Гистограммы распределения размеров зерен нижней (a) и верхней (б) зон сплавления монослоя

Граница между зоной сплавления и зоной с губчатым строением нелинейная. Толщина проплавленного слоя варьируется от 200 до 250 мкм (см. рис. 2). В связи с неоднородностью толщины монослоя и с целью исключения непроплава для послойного сплавления была выбрана толщина насыпки порошка, равная минимальной толщине проплавленного слоя, - 200 мкм.

Анализ излома многослойного образца показал, что процесс его формирования обусловлен наложением слоев друг на друга [15]. При этом процесс наложения слоев сопровождается формированием макродефектов: зон спеченного порошка, крупных усадочных раковин, границ раздела между слоями (рис. 4).

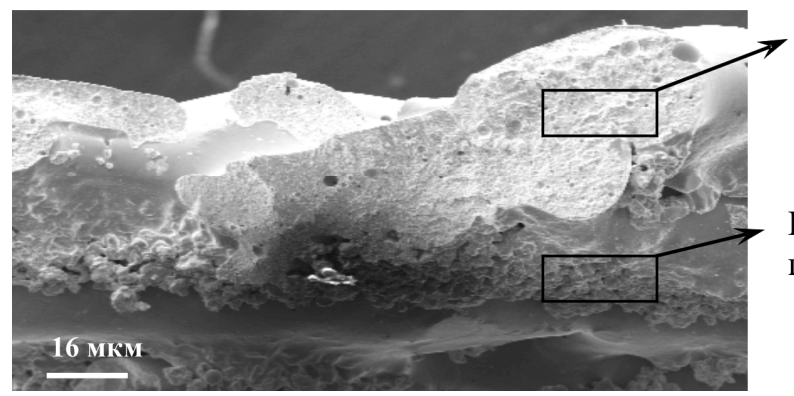

Излом в зоне сплавления

Излом в зоне спеченного порошка

Рис. 4. РЭМ-изображение поверхности излома многослойного образца

Наличие в многослойном образце макродефектов обусловлено особенностью формирования отдельных слоев. При кристаллизации каждого слоя процесс каплеобразования сохраняется, формируя разнотолщинность образца. В образующихся за счет усадки пустотах и по- 
лостях слоя при последующей насыпке сплавляемого материала скапливается порошок. Этот порошок не проплавляется при последующем проходе лазерного пучка и сохраняется в углублениях между слоями в виде зон спеченного порошка. При приготовлении изломов образцов для РЭМ зоны спеченного порошка, являясь самыми непрочными, провоцируют прохождение трещин по своему объему. В результате на РЭМ-изображении излома можно видеть значительное количество участков спеченного порошка (см. рис. 4). В действительности основной объем образца занимает проплавленный материал.

По сечению многослойного образца в каждом слое транслируется структура монослоя. Весь образец состоит из чередующихся вышеописанных зон проплавленного монослоя. Также как и в монослое, каждый сплавленный слой имеет градиентную зеренную структуру (рис. 5).

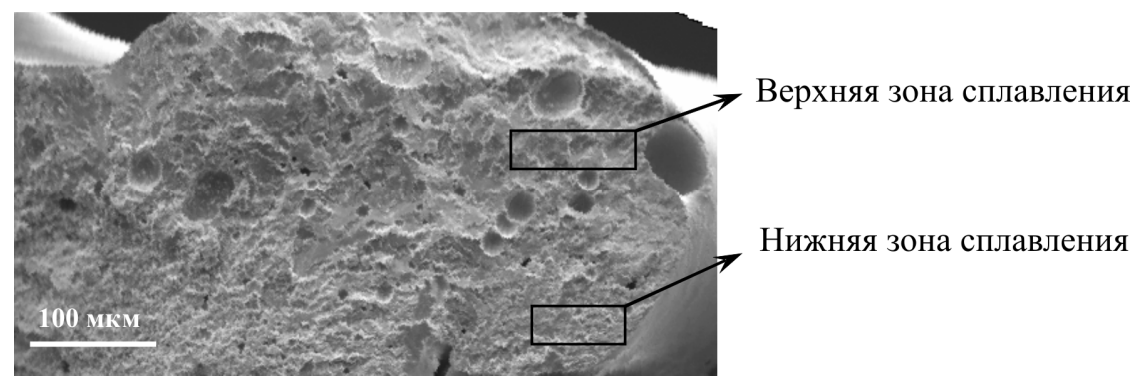

Рис. 5. РЭМ-изображение структуры одного из слоев в многослойном образце

Пористость в проплавленных участках сохраняется, при этом величина пористости снижается за счет снижения доли усадочных раковин в областях спеченного порошка. Снижение пористости обусловлено снижением толщины насыпки для второго и последующих слоев. При наращивании образца насыпанный материал расплавляется полностью (за исключением порошка, попавшего в полости предыдущего слоя) и его кристаллизация начинается не от слоя порошкового материала, а от твердой поверхности предыдущего слоя. Меняющиеся при этом условия затвердевания меняют и условия формирования пористости.

Важным показателем формирования в процессе СЛС сплава $\mathrm{Ti}-\mathrm{Nb}$ является однородность распределения компонентов сплава по сечению слоя и всего образца. Результаты картирования изломов с помощью ЭДМА показали, что в монослое распределение компонентов сплава Ті и $\mathrm{Nb}$ равномерное (рис. 6). 


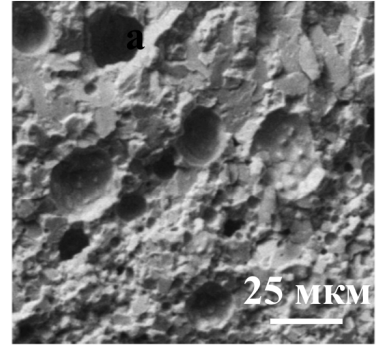

$a$

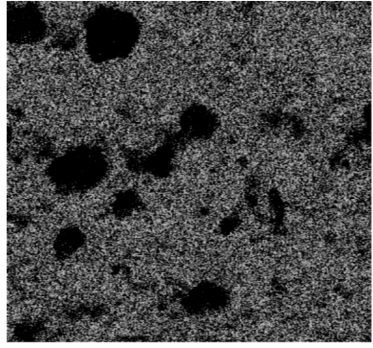

$\sigma$

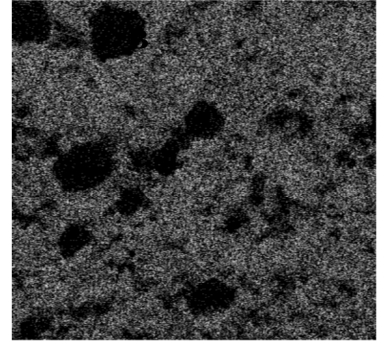

B

Рис. 6. РЭМ-изображение излома монослоя $(a)$ и распределения $\mathrm{Ti}(б)$ и $\mathrm{Nb}($ (в)

Доля ниобия в сплаве изменяется в небольших пределах от 36 до 38 мас. \%. Равномерное распределение элементов и указанное соотношение компонентов $\mathrm{Ti}$ и $\mathrm{Nb}$, соответствующих исследуемому сплаву, имеет место и в многослойном образце.

Сплав в монослое состоит из двух фаз: равновесной фазы $\beta-\mathrm{Ti}-\mathrm{Nb}$ и неравновесной $\alpha^{\prime \prime}$-фазы. Фаза $\beta-\mathrm{Ti}-\mathrm{Nb}$ представляет собой твердый раствор Тi и $\mathrm{Nb}$ с ОЦК-решеткой. На рентгеновских дифрактограммах исследуемых образцов идентифицируются отражения от плоскостей как фазы $\beta$-Ti-Nb, так и $\alpha$ "-фазы (рис. 7). Наличие $\alpha$ "-фазы объясняется неравновесными условиями охлаждения и кристаллизации материала $[3,16]$. На это указывает и формирующаяся мелкозернистая структура (см. рис. 2).

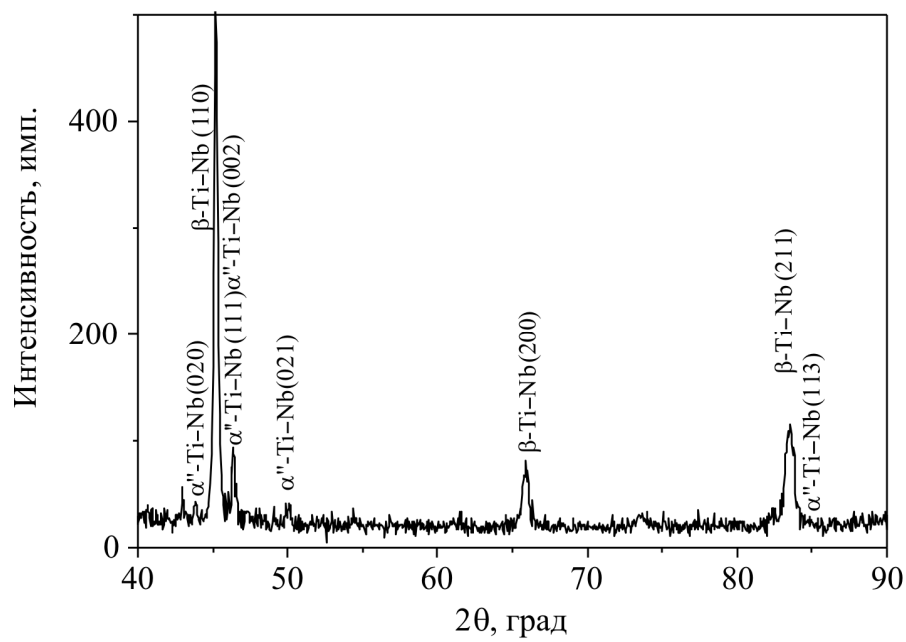

Рис. 7. Фрагмент рентгеновской дифрактограммы для многослойного образца 


\section{Заключение}

В процессе СЛС формируется сплав $\mathrm{Ti}-40$ мас. \% $\mathrm{Nb}$, состоя-

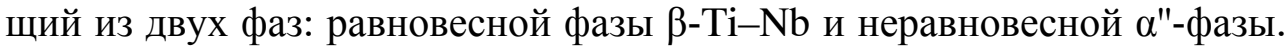
Многослойный образец представляет собой наложенные друг на друга монослои с градиентной структурой. К неоднородности строения ведет неравномерный теплоотвод при кристаллизации каждого слоя. При проведении СЛС требуется создать такие условия охлаждения и кристаллизации расплавившегося материала, когда весь объем слоя, а значит, и всего изделия, будет иметь структуру, подобную верхней зоне монослоя с достаточно мелким зерном и незначительной пористостью.

Работа выполнена при финансовой поддержке Российского научного фонда (грант № 15-19-00191).

\section{Список литературы}

1. Collings E.W. The physical metallurgy of titanium alloys / American Society for Metals. - Ohio, 1984.

2. Influence of cooling rate on microstructure of Ti-Nb alloy for orthopedic implants / C.R. Afonso, G.T. Aleixo, A.J. Ramirez, R. Caram // Materials Science and Engineering. - 2007. - Vol. C 27. - P. 908-913.

3. Investigation of the influence of $\mathrm{Ti}-\mathrm{Nb}$ alloy composition on the structure of the ingots produced by arc melting / Yu.P. Sharkeev, Zh.G. Kovalevskaya, Q. Zhu, M.A. Khimich, E.A. Parilov // Advanced Materials Research. - 2015. - Vol. 1085. - P. 307-311. DOI: 10.4028/ www.scientific.net/AMR.1085.307

4. Theory-guided materials design of multi-phase $\mathrm{Ti}-\mathrm{Nb}$ alloys with bone-matching elastic properties / M. Fri'ak, W.A. Counts, D. Ma, B. Sander, D. Holec, D. Raabe, J. Neugebauer // Materials. - 2012. - Vol. 5. - P. 1853-1872. DOI: $10.3390 / \mathrm{ma} 5101853$

5. Шишковский И.В. Лазерный синтез функциональных мезоструктур и объемных изделий. - М.: Физматлит, 2009. - 417 с.

6. Medical applications of rapid prototyping - a new horizon / B. Vaibhav, R. Darshana, J.B. Shalini, I. Jami // Advanced Applications of Rapid Prototyping Technology in Modern Engineering. - InTech, 2011. DOI: $10.5772 / 20058$ 
7. Laser melting of Ti-45Nb alloy / H. Schwab, K.G. Prashanth, L. Lober, U. Kuhn, J. Eckert Selective // Materials. - 2015. - № 5. - P. 686-694.

8. Ячеистая структура в аустенитных сплавах, полученных методом селективного лазерного плавления / К.О. Базалеева, Е.В. Цветкова, И.Ю. Смуров, И.А. Ядройцев, Е.В. Базалеев, Ю.Г. Костюк // Перспективные материалы. - 2014. - № 3. - С. 55-60.

9. Porous low modulus Ti40Nb compacts with electrodeposited hydroxyapatite coating for biomedical applications / K. Zhuravleva, A. Chivu, A. Teresiak, S., Scudino M. Calin, L. Schults, J. Eckert, A. Gebert // Materials Science and Engineering C. - 2013. - № 33. - P. 2280-2287. DOI: 10.1016/j.msec.2013.01.049

10. Production of porous $\beta$-type Ti-40Nb alloy for biomedical applications: comparison of selective laser melting and hot pressing / K. Zhuravleva, M. Bönisch, K.G. Prashanth, U. Hempel, A. Helth, T. Gemming, M. Calin, S. Scudino, L. Schultz, J. Eckert, A. Gebert // Materials. - 2013. Vol. 6. - P. 5700-5712. DOI: 10.3390/ma6125700

11. Zhang L.G., Fisher J.P., Leong K. 3D Bioprinting and nanotechnology in tissue engineering and regenerative medicine. - Academic Press, 2015. - $392 \mathrm{p}$.

12. Вальтер А.В. Технологии аддитивного формообразования: учеб. пособие. - Томск: Изд-во Том. политехн. ун-та, 2013. - 174 с.

13. Influence of mechanical activation of copper powder on physicomechanical changes in selective laser sintering products / A.A. Saprykin, E.A. Ibragimov, E.V. Babakova, V.I. Yakovlev // AIP Conference Proceedings, 2015. - Vol. 1683. Advanced Materials with Hierarchical Structure for New Technologies and Reliable Structures. DOI: 10.1063/1.4932889

14. Single track formation in selective laser melting of metal powders / I. Yadroitsev, A. Gusarov, I. Yadroitsava, I. Smurov // Journal of Materials Processing Technology. - 2010. - Vol. 210. - P. 1624-1631.

15. Микроструктура и механические свойства на растяжение сплава ВТ6, полученного методом селективного лазерного сплавления / Т.И. Назарова, В.М. Имаев, Р.М. Имаев, С.П. Павлинич // Известия вузов. Физика. - 2015. - Т. 58, № 6. - С. 25-29.

16. Evaluation of physical and mechanical properties of structural components of Ti-Nb alloy / Zh.G. Kovalevskaya, M.A. Khimich, A.V. Belyakov, I.A. Shulepov // Advanced Materials Research. - 2014. - Vol. 1040. - P. 39-42. DOI: 10.4028/www.scientific.net/AMR.1040.39 


\section{References}

1. Collings E.W. The physical metallurgy of titanium alloys. Ohio, American Society for Metals, 1984.

2. Afonso C.R., Aleixo G.T., Ramirez A.J., Caram R. Influence of cooling rate on microstructure of $\mathrm{Ti}-\mathrm{Nb}$ alloy for orthopedic implants. Materials Science and Engineering, 2007, vol. C 27, pp. 908-913.

3. Sharkeev Yu.P., Kovalevskaya Zh.G., Zhu Q., Khimich M.A., Parilov E.A. Investigation of the influence of Ti-Nb alloy composition on the structure of the ingots produced by arc melting. Advanced Materials Research, 2015, vol. 1085, pp. 307-311. DOI: 10.4028/www.scientific. net/AMR.1085.307

4. Fri'ak M., Counts W.A., Ma D., Sander B., Holec D., Raabe D., Neugebauer J. Theory-guided materials design of multi-phase Ti-Nb alloys with bone-matching elastic properties. Materials, 2012, vol. 5, pp. 1853-1872; DOI: $10.3390 /$ ma5101853

5. Shishkovskii I.V. Lazernyi sintez funktsional'no-gradientnykh mezostruktur i ob"emnykh izdelii [Laser synthesis of functionally graded mesostructures and bulk products]. Moscow: Fizmatlit, 2009. 417 p.

6. Vaibhav B., Darshana R., Shalini Jain B., Jami I. Medical applications of rapid prototyping - a new horizon. Advanced Applications of Rapid Prototyping Technology in Modern Engineering. InTech, 2011. DOI: $10.5772 / 20058$

7. Schwab H., Prashanth K.G., Lober L., Kuhn U., Eckert J. Selective laser melting of Ti-45Nb alloy. Materials, 2015, no. 5, pp. 686-694.

8. Bazaleeva K.O., Tsvetkova E.V., Smurov I.Yu., Yadroitsev I.A., Bazaleev E.V., Kostiuk Yu.G. Iacheistaia structura v austenitnykh splavakh, poluchennykh metodom selektivnogo lazernogo plavleniia [The cellular structure in austenitic alloys obtained by selective laser melting]. Perspective materials, 2014, no. 3, pp. 55-60.

9. Zhuravleva K., Chivu A., Teresiak A., Scudino S., Calin M., Schults L., Eckert J., Gebert A. Porous low modulus Ti40Nb compacts with electrodeposited hydroxyapatite coating for biomedical applications. Materials Science and Engineering C, 2013, no. 33 pp. 2280-2287. DOI: 10.1016/j.msec. 2013.01.049

10. Zhuravleva K., Bönisch M., Prashanth K. G., Hempel U., Helth A., Gemming T., Calin M., Scudino S., Schultz L., Eckert J., Gebert A. Produc- 
tion of porous $\beta$-type $\mathrm{Ti}-40 \mathrm{Nb}$ alloy for biomedical applications: comparison of selective laser melting and hot pressing. Materials, 2013, vol. 6, pp. 5700-5712. DOI: $10.3390 / \mathrm{ma} 6125700$

11. Zhang L.G., Fisher J.P., Leong K. 3D Bioprinting and nanotechnology in tissue engineering and regenerative medicine. Academic Press, 2015. 392 p.

12. Val'ter A.V. Tekhnologii additivnogo formoobrazovania [Technologies of additive shaping]. Tomskii politekhnicheskii universitet, 2013. $174 \mathrm{p}$.

13. Saprykin A.A., Ibragimov E.A., Babakova E.V., Yakovlev V.I. Influence of mechanical activation of copper powder on physicomechanical changes in selective laser sintering products. AIP Conference Proceedings. Advanced Materials with Hierarchical Structure for New Technologies and Reliable Structures, 2015, vol. 1683. DOI: 10.1063/1.4932889

14. Yadroitsev I., Gusarov A., Yadroitsava I., Smurov I. Single Track formation in selective laser melting of metal powders. Journal of Materials Processing Technology, 2010, vol. 210, pp. 1624-1631.

15. Nazarova T.I., Imaev V.M., Imaev R.M., Pavlinich S.P. Mikrostruktura i mekhanicheskie svoistva na rastiazhenie splava VT6, poluchennogo metodom selektivnogo lazernogo splavleniia [Microstructure and mechanical tensile properties of VT6 alloy obtained by the method of selective laser melting]. Izvestiia vysshikh uchebnykh zavedenii. Fizika, 2015, vol. 58, no. 6 , pp. 25-29.

16. Kovalevskaya Zh.G., Khimich M.A., Belyakov A.V., Shulepov I.A. Evaluation of physical and mechanical properties of structural components of Ti-Nb alloy. Advanced Materials Research, 2014, vol. 1040, pp. 39-42. DOI: 10.4028/www.scientific.net/AMR.1040.39

Получено 27.01.2016

\section{Об авторах}

Ковалевская Жанна Геннадьевна (Томск, Россия) - кандидат технических наук, доцент Национального исследовательского Томского политехнического университета, ведущий инженер Института физики прочности и материаловедения СО РАН; e-mail: zhanna_kovalevskaya@mail.ru.

Химич Маргарита Андреевна (Томск, Россия) - инженер Института физики прочности и материаловедения СО РАН, аспирант Нацио- 
нального исследовательского Томского государственного университета; e-mail: khimich@ispms.tsc.ru.

Шаркеев Юрий Петрович (Томск, Россия) - доктор физикоматематических наук, профессор Национального исследовательского Томского политехнического университета, заведующий лабораторией физики наноструктурных биокомпозитов Института физики прочности и материаловедения CO РАН; e-mail: sharkeev@ispms.tsc.ru.

Бабакова Елена Владимировна (Юрга, Россия) - аспирант Юргинского технологического института Национального исследовательского Томского политехнического университета; e-mail: babakova @tpu.ru.

\section{About the authors}

Zhanna G. Kovalevskaia (Tomsk, Russian Federation) - Ph. D. in Technical Sciences, Associate Professor, National Research Tomsk Polytechnic University, Chief Engineer, Institute of Strength Physics and Materials Science of the Siberian Branch of the Russian Academy of Sciences; email: zhanna_kovalevskaya@mail.ru.

Margarita A. Khimich (Tomsk, Russian Federation) - Engineer, Institute of Strength Physics and Materials Science of the Siberian Branch of the Russian Academy of Sciences, Postgraduate Student, National Research Tomsk State University; e-mail: khimich@ispms.tsc.ru.

Iurii P. Sharkeev (Tomsk, Russian Federation) - Doctor of Physical and Mathematical Sciences, Professor, National Research Tomsk Polytechnic University, Head of Laboratory of Nanostructured Biocomposites, Institute of Strength Physics and Materials Science of the Siberian Branch of the Russian Academy of Sciences; e-mail: sharkeev@ispms.tsc.ru.

Elena V. Babakova (Yurga, Russian Federation) - Postgraduate Student, Yurga Institute of Technology of National Research Tomsk Polytechnic University Affiliate; e-mail: babakova@tpu.ru. 